\title{
TEMPORAL AND SPATIAL SCALES OF LAKE PROCESSES. PART 2: INTERACTION OF PHYSICAL AND ECOLOGICAL SCALES AND APPLICATION OF SCALING CONCEPTS TO GREEK LAKES
}

\author{
I. PAPADIMITRAKIS* \\ A. CHIONI
}

\author{
National Technical University of Athens (NTUA) \\ School of Civil Engineering \\ Water Resources and Environmental Engineering Div., \\ 5, Heroon Polytechniou St., Zografos 15780, Athens, Greece
}

Received: $11 / 06 / 10$

Accepted: 29/07/11 *to whom all correspondence should be addressed: e-mail: ypapadim@central.ntua.gr

\begin{abstract}
The temporal and spatial scaling concepts related to basic physical and ecological lake processes and the associated non-dimensional parameters that govern the various flow regimes, developed in lakes and reviewed in Part 1 of our companion paper (Papadimitrakis, 2011), are applied to lakes Pamvotis and Vegoritis, two water enclosures located in the Northern Greece having different bathymetry and morphology and forced by dissimilar external conditions. This paper begins with a description of the interaction of physical and biological processes in lakes (the latter being described in Part 1) and proceeds with the application of scaling concepts to the above lakes. From these two applications, several interesting conclusions are drawn by comparing the similarities and differences shown in the variation, with time, of these important scales and non-dimensional parameters and how the latter affect the various lake flow regimes.
\end{abstract}

KEYWORDS: Lake processes, physical scales, ecological scales, interaction of scales, lake ecohydrodynamics, flow regime-scale interrelation.

\section{INTERACTION OF PHYSICAL - BIOLOGICAL PROCESSES IN LAKES}

Having described, in Papadimitrakis (2011) and in some detail, the physical and ecological processes that occur in lakes and other similar aquatic environments, as a response to external and internal forcing(s), it was felt appropriate to elaborate here on the interaction of these two processes and, then, utilize this latter experience to draw some useful conclusions from the application of spatial-temporal scaling concepts to lake Pamvotis and Vegoritis. The physical processes that govern the behaviour of lake thermodynamics and hydrodynamics transport and mix pollutants and, thus, transport nutrients and other living organisms in the aquatic environment. Vertical transports by these processes (characterized by spatial scales, proceeding from the largest basin scale down to the viscous scales in which individual zooplankton, phytoplankton and bacteria function) influence the biological activity in lakes. They mainly affect lake (i.e., aquatic) ecology and water quality by: a) controlling the supply of dissolved inorganic nutrients to the surface mixed-layer (SML), and particularly to the upper sunlit layer (the euphotic zone), and b) regulating the thickness of the SML and, thereby, the light levels experienced by phytoplankton. The reader interested in the importance of transport and mixing on ecological processes should peruse the corresponding section of Imberger (1998), and more specifically the articles by Imboden (1998) and Straskraba (1998) on the influence of biogeochemical processes on the physics of lakes and on the coupling of hydrobiology and hydrodynamics in lakes and reservoirs, respectively.

How do the various (generated) lake motions of large (basin scale) and smaller scale influence water quality and its attributes in lakes (or reservoirs) as, for example, the nutrient and heavy metal cycling, the behavior of biologically and chemically active particles (say, smaller than $10 \mu \mathrm{m}$ ), and the primary production? Since, in the main water body, the Kolmogorov length scale $\eta_{v} \approx O\left(10^{-3} \mathrm{~m}\right)$, 
it follows that the scale of the smallest eddy will be about one to two $\mathrm{cm}$ and a huge difference, in size, between the smallest scale motion and the active particles will exist; the motion will appear as a simple shear flow to all such particles.

At the basin scale and mesoscale, vertical motions can deform the nutricline, i.e. the base of SML, towards the lake surface, causing it to be more susceptible to surface-driven mixing processes and making phytoplankton to be contained nearer the lake surface where it experiences high light levels. Furthermore, upwelling provides a steady (on average) supply of nutrients, in the SML, required for phytoplankton photosynthesis.

On smaller scales, vertical processes associated with the large eddy structure of turbulence (Langmuir cells), in the SML, play an important role in shaping specific ecosystems. Thus, at scales equal to or smaller than the SML thickness, vertical motions are active agents that mix nutrients into the mixed-layer and advect individual organisms and particles over vertical gradients, in the subsurface light fields.

Processes at the smallest scales of (relative) motion in the lake, which are associated with the dissipation of turbulent kinetic energy, may play a major role in the dynamics of individual organisms or particles, and their interactions. Where the nutricline (a region where nutrient concentration profiles exhibit a strong gradient in the vertical direction) is shallow, the sunlit upper layer of the lake can be periodically resupplied with nutrients, by surface-driven turbulent motions with vertical scales typically comparable to the depth of SML. With a simplistic separation of the effects of these energetic motions, the upper lake planktonik community can be advected by the (larger) energycontaining scales and sheared by the (smaller) dissipation scales.

The large eddies of the SML affect the embedded biological community in a variety of ways. Where such structures are present, water properties quickly become vertically homogenized (Weller and Prize, 1988). Small-scale biological patchiness may be similarly reduced (Owen, 1989; Tiselius et al., 1994). Infrequent occurrences of larger overturns at the base of SML provide pulses of nutrient resupply, while large-eddy structures advect phytoplankton in an exponentially varying light field, with time scales comparable with those of light adaptation.

Fluid motion on the scales of aquatic organisms is due to turbulence. Since the swimming speed of small aquatic organisms is small, they become increasingly susceptible to ambient fluid velocities. The possibility of interaction between gradients produced by turbulence and biological organisms depends upon possible overlap in their spatial scales. Since the smallest gradient scales depend on the dissipation rate of turbulent kinetic energy, $(\varepsilon)$, and decrease when $\varepsilon$ increases, the degree of overlap will be a complex function of organism size and of all factors that drive turbulence in the upper SML of the lake. The effects of turbulence on organisms will vary with the scale of the organism and the strength of turbulence. The very small organisms, like bacteria, live at low Reynolds numbers (Pedley and Kessler, 1992). For somewhat larger scales of O(10-100 $\mu \mathrm{m})$, deformation of chemical gradients associated with the Stokes flow about an organism (assumed spherical), that either sinks or swims at a modest rate of $\sim 1$ diameter $\mathrm{s}^{-1}$, can lead to a significant increase of the diffusive flux of that organism.

Turbulence also affects the residence time of inanimate particles in the SML (Lande and Wood, 1987). The time spent by particles, at various depths of this layer, is determined by the particle sinking rate and the vertical distribution of turbulence intensity. Particles reaching the pycnocline may be reintroduced in the SML by turbulent activity in the underlying pycnocline. This depends on the strength of mixing, in the pycnocline, and the sinking speed. It seems obvious that at large enough turbulence intensity, turbulent shear will also act to break up the relative fragile aquatic particles and, thus, contributes to limit the maximum size of aggregates. Recent observations of phytoplankton concentrations, with sophisticated instrumentation, indicate sharp gradients in chlorophyll fluorescence, in the pycnocline, and that small-scale patchiness is the norm for small plankton communities. The degree of patchiness is also related to turbulence intensity. It is smaller at high wind speeds (strong wind mixing) and during the night (strong convective mixing).

Similar conclusions were reached by Maar et al. (2003) who, using a high resolution sampler for simultaneous measurements of chlorophyll and of turbulence microstructure in the Skagerrak and in the North Aegean seas, confirmed the existence of chlorophyll maximum in the water column; these authors also found that, for the weak swimmers of plankton community, there was a significant decrease in their variability (as quantified by their coefficient of variation, CV) with increasing 
turbulence, whereas the variability of stronger swimmers was uncorrelated with the level of turbulent diffusivity. It is worth noting, here, that the ability of organisms to form and remain in a patch, in the turbulent water column, depends on their swimming ability, the turbulent diffusivity, and the nature of an "attractor" present in the water environment (e.g., a patch of food, a chemical, or a specific light intensity) that governs their swimming behavior.

It appears that for chemically active particles the rate of strain, $\gamma$, determines the rate of particle amalgamation and breakup (O'Melia and Tiller, 1993); $Y$ influences strongly the rate of growth of plankton and of biologically active particles (Thomas and Gibson, 1990); large values of this parameter inhibit growth. On the other hand, the water transports these minute particles that have not formed colonies, as it moves throughout the lake (since their rise or fall velocities are by far smaller than the slowest fluid motion), and brings them into different light regimes or to depths with different chemical properties. The path along which particles travel (the so called "flux path") is of paramount importance to limnologists.

Differential absorption of heat, across the lake surface, may also cause tearing (apart) of phytoplankton blooms by self-generated convective motions caused by the interaction of convection and growth dynamics of the various species of phytoplankton.

Ecological processes seldom influence hydrodynamics, particularly at large spatial scales. That may, however, happen through the modification of either the bottom roughness and, hence, friction, or by the development of benthic population, or that of the baroclinic circulation caused by changes in the vertical structure of the lake water temperature; the latter arises from a biological increase of the light extinction coefficient. Such feedbacks, from ecology to hydrodynamics, can be significant only at small scales and in very particular situations. In general, hydrodynamic conditions form a prescribed environment for ecosystems; that is also true in pollution studies. Pollution problems in lakes often arise from waste dumping. Even when wastes are not toxic, their disposal in the lake gives rise to considerable local increases in turbidity and sediment deposition on the lake bed. Turbidity, however, reduces the depth of penetration of sunlight (and the intensity of chlorophyll synthesis) and, thus, affects external forcing and, indirectly, the lake hydrodynamics.

Imboden (1998) has pointed out that, in some cases, organisms may influence the physics of an aquatic environment; this might be accomplished, for example, by the additional input of TKE by swimming fish, the intensification of vertical stratification resulting from light absorption by large concentrations of phytoplankton and, in meromictic lakes, by the vertical convection induced by sinking bacteria at the oxic-anoxic interface.

Straskraba (1998) has stressed the differences in both the coupling of hydrobiology and hydrodynamics and the behavior of various limnological variables found in lakes and reservoirs due to the different retention times and some differences in the hydrodynamics of the two types of water bodies caused, respectively, by the surface outflow from lakes and the deep outflow from reservoirs. Straskraba (1998) also found that increasing amounts of phytoplankton result in shallower thermoclines and warmer surface layers, and concluded that a positive feedback exists between phytoplankton development and reservoir hydrodynamics.

The activity of microorganisms (algae and bacteria) appears to also depend on population density, as the former drops steeply with increasing biomass, a feature that explains the differences in activity between reduced and dense populations. Furthermore, hydrodynamic conditions affect zooplankton behavior as both macro- and micro-level processes of mixing and light conditions determine the distribution, behavior, migration, feeding and predation by (and of) zooplankton, as well as the morphology of some zooplankton species.

\section{APPLICATION OF SCALING CONCEPTS TO LAKES PAMVOTIS AND VEGORITIS}

The ideas on time and length scales and the associated dimensionless numbers, presented in Papadimitrakis (2011), were applied to lakes Pamvotis and Vegoritis in order to characterize the flow regimes and physical processes occurring in these lakes during 1984 (for Pamvotis) and a period covering part of 1999 and part of 2000 (for Vegoritis). During the respective time periods both, results from simulations of the water quality in these water impoundments and corresponding field observations, were available for further analysis and utilization (see Papadimitrakis et al., 1996a; b; Chioni, 2005; Papadimitrakis and Chioni, 2006). Pamvotis is a shallow, flat bottom lake with an apple like shape in the horizontal plane. It has a maximum depth of about $9.2 \mathrm{~m}$, an average depth of 6.1 
$\mathrm{m}$ and covers an area of $22 \mathrm{~km}^{2}$. Its average length and width are about 7.2 and $3 \mathrm{~km}$, respectively. Lake Pamvotis is located in the Northwestern Greece, at the Northern border of loannina city. Vegoritis is a deep, potato shape lake in the horizontal plane with a maximum depth of about $45 \mathrm{~m}$, an average depth of $20 \mathrm{~m}$, a maximum length and width of about 12 and $5.5 \mathrm{~km}$, respectively, and covers an area of $39 \mathrm{~km}^{2}$. It is located near the city of Kozani which, geographically, also belongs to the Northern part of Greece. The surrounding watershed and lake characteristics, for both lakes, are also described in the above references.

In order to estimate the (spatially) average length scales $I_{c}, I_{o}, I_{p}, \eta_{V}$ and $\eta_{B}$ and the corresponding (spatially) average time scales, over the mixed-layer depth, $h$, the (likewise average) TKE dissipation rate, $\varepsilon$, and the buoyancy frequency, $N$, must be obtained first. With regard to $\varepsilon$, and since no dissipation measurements were available, this was accomplished by utilizing: a) the concept of relative efficiencies of the various processes occurring in lakes (as described in Imberger and Patterson, 1990), and b) the results of numerical simulations of water quality in both lakes, described in the above references, using DYRESM-WQ and DYRESM-CAEDYM, respectively, two process oriented software developed by the Centre of Water Research of the University of Western Australia. These results provide, among other quantities, the height of the surface mixed layer, $h$, entering the calculations of $\varepsilon$, as seen below.

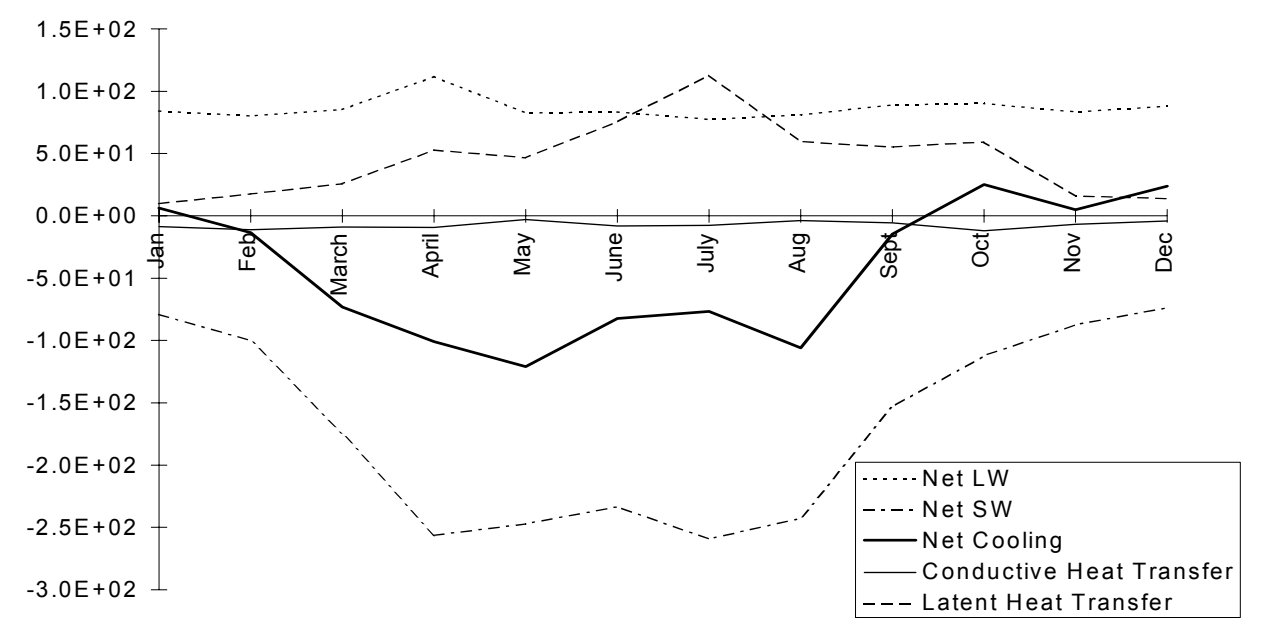

Figure 1a. Monthly variation of surface heat fluxes in lake Pamvotis, during 1984

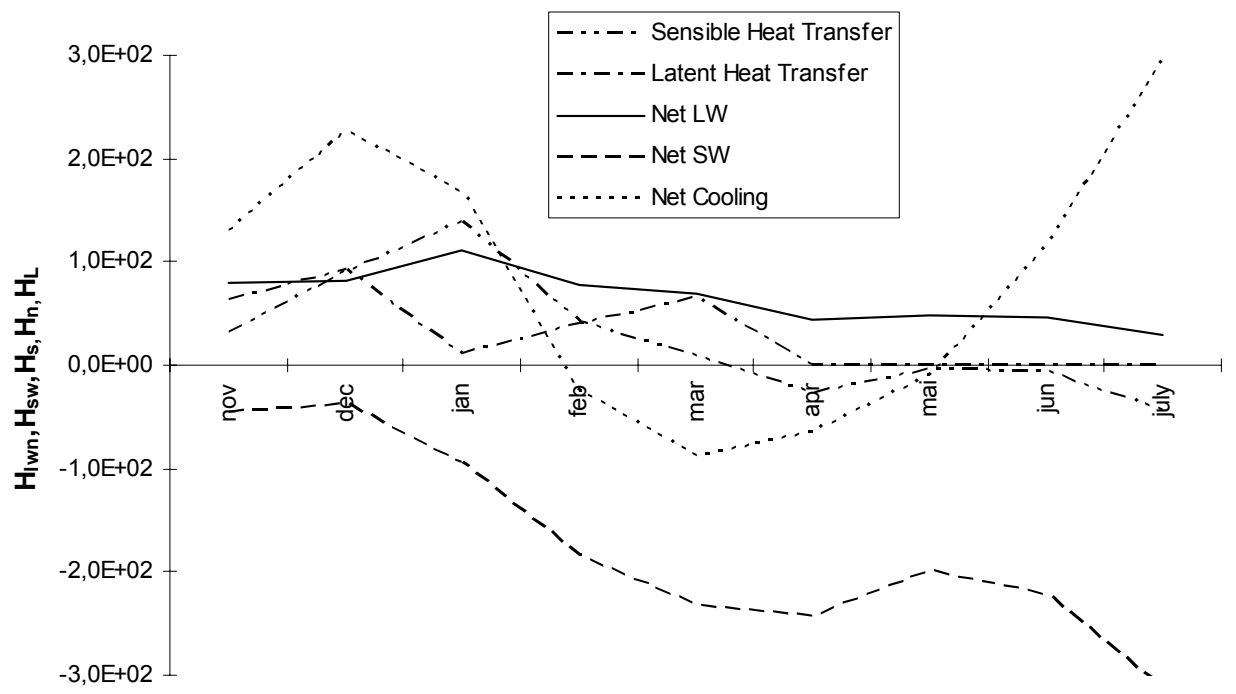

Figure 1 b. Monthly variation of surface heat fluxes in lake Vegoritis, during 1999-2000

According to Imberger and Patterson (1990), an average value of $\varepsilon$, in the surface layer, may be estimated as: $\varepsilon=C_{E}\left(w_{*}^{3}+\eta^{3} u_{*}^{3}\right) / h$. Here, $w_{*}\left[=\left(\alpha g h H_{n} / \rho_{O} C_{p_{w}}\right)^{1 / 3}\right]$ is a convective velocity scale and $u_{*}$ is (again) the water friction velocity, $a\left(\approx 2.57 \times 10^{-4}{ }^{\circ} \mathrm{C}^{-1}\right)$ is the thermal expansion coefficient of 
water, $C_{p w}\left(\approx 4179 \mathrm{~J} \mathrm{~kg}^{-1}{ }^{\circ} \mathrm{C}^{-1}\right.$ ) is the specific heat of water (under constant pressure), $\rho_{\circ}$ is the epilimnion density and $H_{n}$ is the net heat flux at the lake's surface; $\eta(=1.23)$ is a parameter reflecting the relative efficiency of convective overturn and wind stirring, whereas $C_{E}(=1.15)$ is another parameter reflecting the relative efficiency of the former processes with respect to mixedlayer dissipation. From the field input data and the simulation results $u_{*}, N, w_{*}$ and $h$ were estimated, and from them the dissipation rate $\varepsilon$ and the corresponding length and time scales, as well as the dimensionless numbers $\mathrm{Fr}_{t}, \mathrm{Re}_{t}, \mathrm{Gr}$, and $\mathrm{Fr}_{y}$, were obtained.

Figures $1(a, b)$ and $2(a, b)$ show the monthly variation of surface heat fluxes (in $\mathrm{W} \mathrm{m}^{-2}$ ) and of the external forcing velocities $u_{*}, w_{*}$ plus that of the combined velocity scale $q_{*}\left(=w_{*}^{3}+\eta^{3} u_{*}^{3}\right)^{1 / 3}$, all in $\mathrm{m} \mathrm{sec}^{-1}$, for lake Pamvotis during 1984 and for lake Vegoritis during 1999-2000. These fluxes include the sensible and latent heat transfers $\mathrm{H}_{\mathrm{s}}$ and $\mathrm{H}_{\mathrm{L}}$, respectively, the incident (from the water vapor in the atmosphere, etc.), $\mathrm{H}_{1}$, and back long wave radiation $\mathrm{H}_{2}$, and the incident (direct) short-wave radiation $\mathrm{H}_{\mathrm{sw}}$. The surface fluxes $\mathrm{H}_{\mathrm{S}}, \mathrm{H}_{\mathrm{L}}, \mathrm{H}_{1}$ and $\mathrm{H}_{2}$ are estimated by the following relationships: $H_{s}=C_{s} \rho_{\alpha} C_{p a} U_{10}\left(T_{s}-T_{10}\right), \quad H_{L}=C_{L} \rho_{\alpha} L_{w} U_{10}\left(Q_{s}-Q_{10}\right), \quad H_{1}=-5.18 \times 10^{-13}\left(1+0.17 C_{N}^{2}\right)\left(273+T_{10}\right)^{6}$, $\mathrm{H}_{2}=5.23 \times 10^{-8}\left(273+\mathrm{T}_{\mathrm{s}}\right)^{4}$. Here $\mathrm{T}_{\mathrm{s}}$ and $\mathrm{T}_{10}$ are the water surface temperature and the air temperature at the height of $10 \mathrm{~m}$ above M.W.L. (both in ${ }^{\circ} \mathrm{C}$ ), $\mathrm{Q}_{\mathrm{s}}$ is the saturation specific humidity (in $\mathrm{kg}$ of water moister $/ \mathrm{kg}$ of air-water moisture) at $T_{s}$, and $Q_{10}$ is the specific air humidity at the height of $10 \mathrm{~m}$. For latent heat transfer to become effective: $Q_{s}\left(T_{s}\right)>Q_{10}\left(T_{10}\right)$ (otherwise $H_{L}=0$ ). $C_{N}$ is the fraction of sky covered by clouds, $\mathrm{C}_{\mathrm{s}} \approx \mathrm{C}_{\mathrm{L}} \approx 1.45 \times 10^{-3}, \mathrm{~L}_{\mathrm{W}}\left(\approx 2.4 \times 10^{6} \mathrm{~J} \mathrm{~kg}^{-1}\right)$ is the latent heat of evaporation and $\mathrm{C}_{\mathrm{pa}}$ $\left(\approx 1012 \mathrm{~J} \mathrm{~kg}^{-1}{ }^{\circ} \mathrm{C}^{-1}\right)$ is the specific humidity of air at constant pressure. Some of these constants (e.g., $\mathrm{C}_{\mathrm{pd}}$, etc.) may vary slightly with temperature and representative average values have been used in the subsequent calculations. The saturation specific humidity $Q_{s}$, at the surface temperature $T_{s}$, may either be obtained from Thermodynamic Tables or estimated according to empirical relations as a function of $T_{s} . Q_{10}$ maybe estimated as the ratio: $\rho_{u} /\left(\rho_{u}+\rho_{\xi}\right)$, where $\rho_{u}$ and $\rho_{\xi}$ are, respectively, the densities of water vapour and dry air at $T_{10} ; \rho_{u}=f . \rho_{s}$, where $\rho_{s}$ is the saturation vapour density at $T_{10}$ and $f$ is the relative humidity that may also be obtained from the saturation specific humidity at $T_{10}$ and thermodynamic tables; $\rho_{\mathrm{s}}$ maybe obtained from the perfect gas state equation that relates $\rho_{\mathrm{s}}$ with $p_{s}, R_{u}$ and $T_{10}\left\{i . e ., \rho_{s}=p_{s} /\left(R_{u} T_{10}\right)\right\}$, where $p_{s}$ is the saturation vapour pressure and $R_{u}$ is the gas constant for vapour $\left(\approx 461 \mathrm{~J} \mathrm{~kg}^{-1}{ }^{\circ} \mathrm{K}^{-1}\right) ; p_{\mathrm{s}}$ maybe calculated as a function of $\mathrm{T}_{10}$ obtained either from Thermodynamic Tables (in the form of a $6^{\text {th }}$ order polynomial of $T_{10}$ - cf. Table 4.3 of Curry and Webster, 1999) or other empirical relationships; $\rho_{\xi}$ may be readily calculated from $T_{10}$. It is noted that, in general, $\rho_{\alpha}=\rho_{\xi}+\rho_{u}$ (in $\mathrm{kg} \mathrm{m}^{-3}$ ) and that $\rho_{\alpha} \leq \rho_{\xi} . H_{s w}, C_{N}, T_{10}$ and $U_{10}$ data were obtained either from the National Weather Center, in Athens, or from the meteo stations located closer to the lakes considered; $T_{s}$ was obtained from the simulation results of water temperature at the surface of each lake. The net heat flux, at the surface, used in the calculation of $\mathrm{w}_{*}$ is, then, estimated as: $\mathrm{H}_{\mathrm{n}}=\mathrm{H}_{\mathrm{s}}+\mathrm{H}_{\mathrm{L}}+\mathrm{H}_{1}+\mathrm{H}_{2}+\mathrm{H}_{\mathrm{sw}}$.

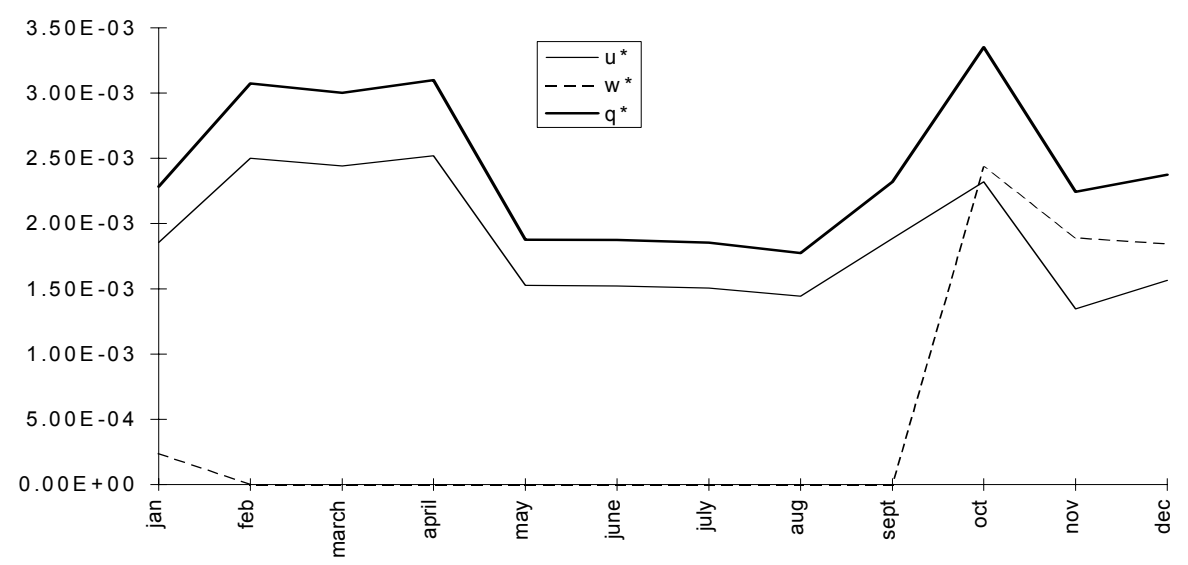

Figure 2a. Monthly variation of $\mathrm{u}_{*}, \mathrm{w}_{*}, \mathrm{q}_{*}$ in lake Pamvotis, during 1984 


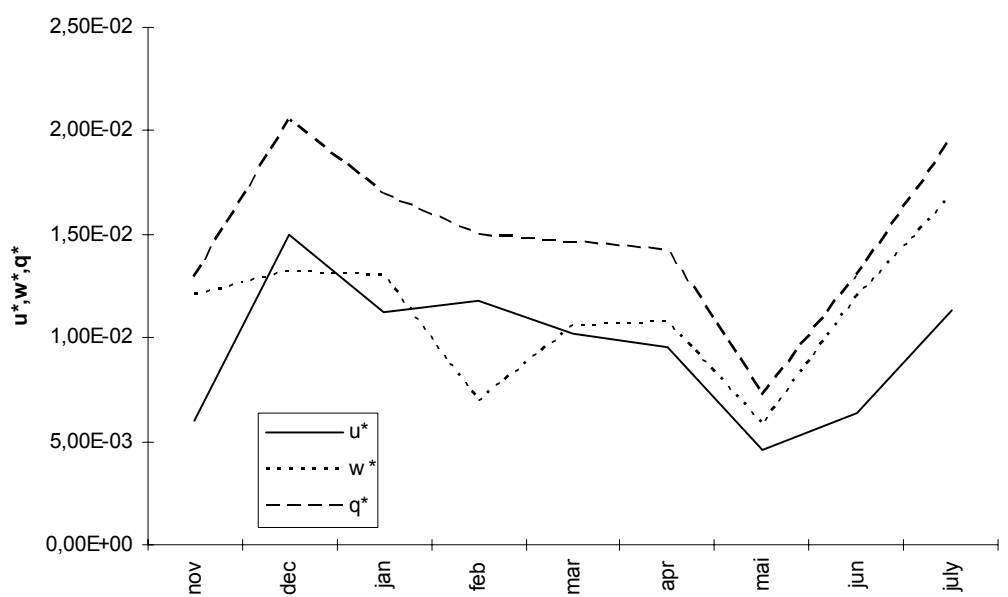

Figure $2 b$. Monthly variation of $\mathrm{u}^{*}, \mathrm{w}^{*}, \mathrm{q}^{*}$ in lake Vegoritis, during 1999-2000

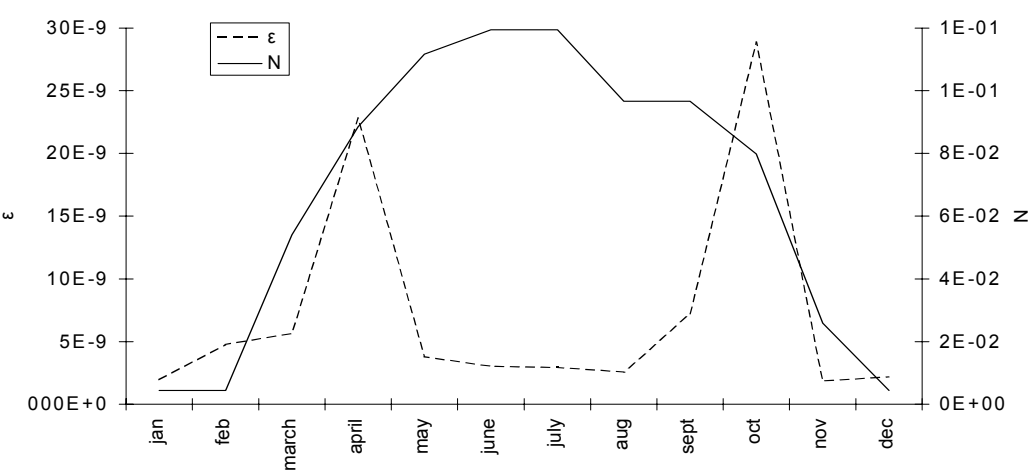

Figure 3a. Monthly variation of $\varepsilon$ and $\mathrm{N}$ in lake Vegoritis, during 1984.

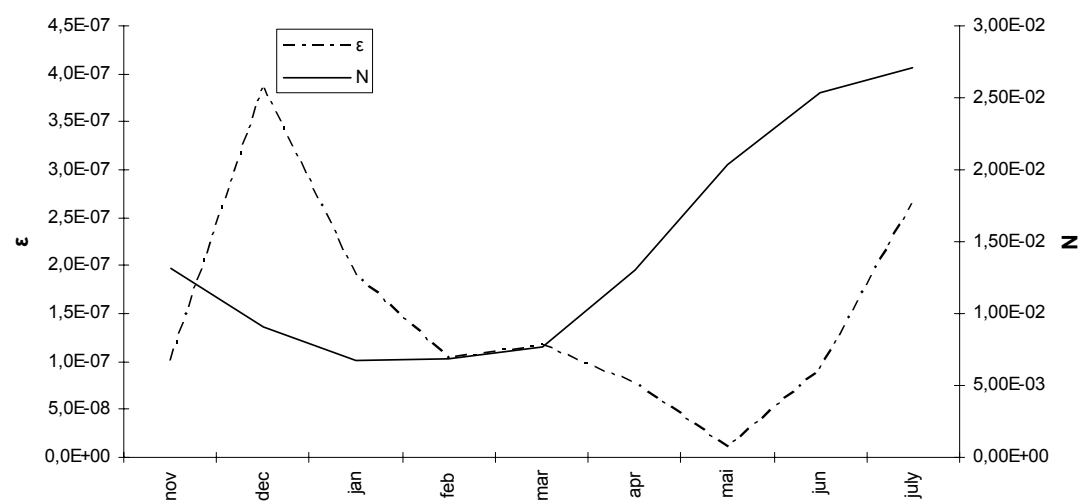

Figure 3b. Monthly variation of $\varepsilon$ and $N$ in lake Vegoritis, during 1999-2000

\section{RESULTS - DISCUSSION}

Figures $3(a, b)$ show the corresponding time variations of $\varepsilon$ (in $\left.\mathrm{m}^{-2} \sec ^{-3}\right)$ and $N\left(\right.$ in $\left.\sec ^{-1}\right)$ for these two lakes. Similar variations of the various length scales (in meters), and their ratios, show Figures $4(a, b, c), 5(a, b, c)$ and $6(a, b)$. Figures $7(a, b, c)$ present the monthly variation of the corresponding time scales (in sec), whereas Figures $8(a, b)$ and $9(a, b, c)$ show the monthly variation of the nondimensional parameters $F_{t}, F_{r}, \operatorname{Re}_{t}, L_{N}$ and $W$, over the simulation time periods.

As seen from Figures $4 a, 5 a$ and $8 a$, for lake Pamvotis during $1984, I_{O}<I_{C}, I_{C}$ remains nearly constant with a value of about $0.5 \mathrm{~m}$ and $F r_{t}<1$. During most time in fall, in winter and early in spring, $F r_{Y}>1$, whereas during the remaining period (of thermal stratification) $F r_{Y}<1$. During the latter time $F r_{t}$ attains quite low values, whereas during the overturn period $F r_{t}$ approaches unity. Active turbulence occurs always at scales smaller than $I_{O}$, or smaller than about $0.25 \mathrm{~m}$, as from Figure $4 a$ it becomes obvious that the maximum active turbulent scale $I_{O}$, attained by mid-February, 
does not exceed $0.25 \mathrm{~m}$. In this range of scales (i.e. $<0.25 \mathrm{~m}$ ), the flow field remains turbulent throughout the year. Since during thermal stratification $F r_{Y}<1$, it is expected that internal wave activity will then become more important than turbulent mixing. Yet, the transport of fresh water and nutrients, during the corresponding period, will be limited as internal waves transport momentum but not mass. Conversely, $\mathrm{Fr}_{Y}>1$ during the overturning period and active turbulence with scales, ranging from about $0.05 \mathrm{~m}$ to $0.25 \mathrm{~m}$, is primarily responsible for mixing. Albeit small, these $I_{O}$ scales are always greater than $\eta_{V}$, implying that the motion in the lake is not completely damped by buoyancy and viscosity in the corresponding period.

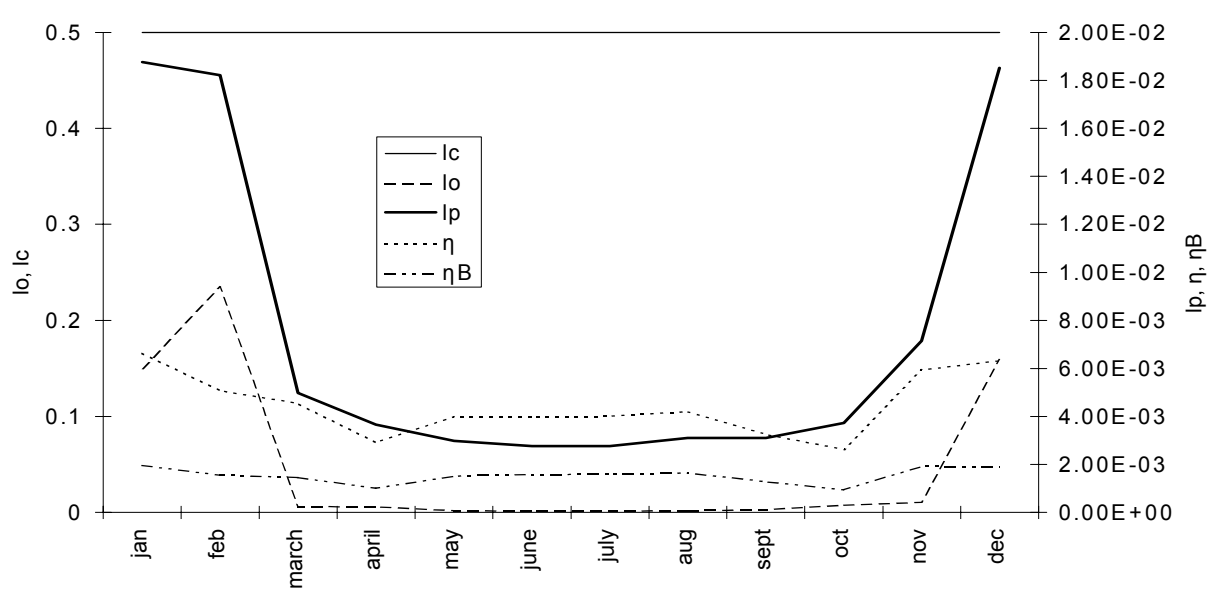

Figure $4 a$. Monthly variation of length scales $I_{C}, l_{O}, I_{p}, \eta_{v}, \eta_{B}$ in lake Pamvotis, during 1984

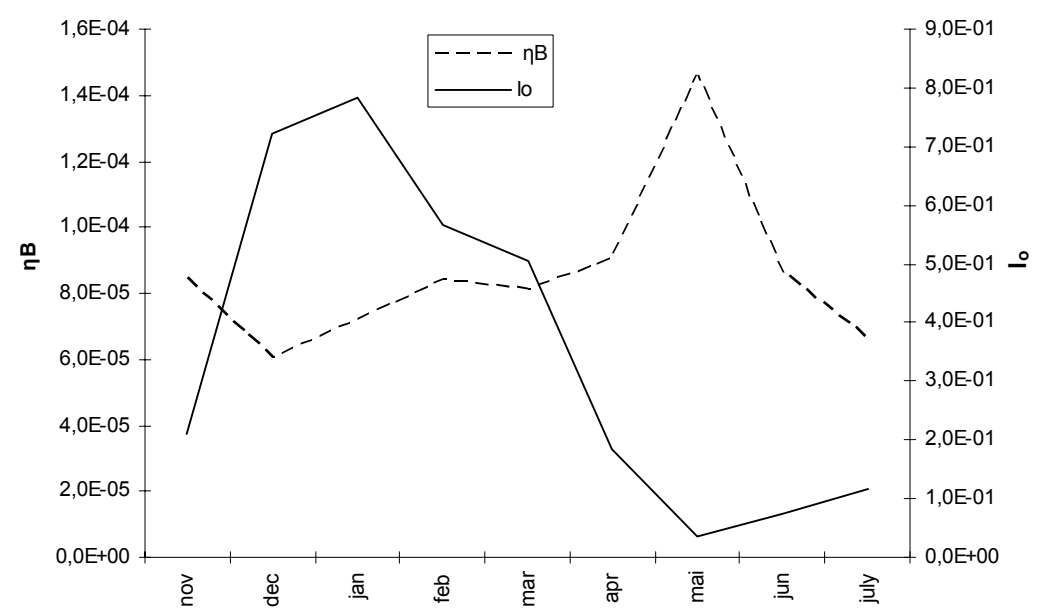

Figure $4 b$. Monthly variation of length scales $\mathrm{l}_{\mathrm{O}}, \eta_{\mathrm{B}}$ in lake Vegoritis, during 1999-2000

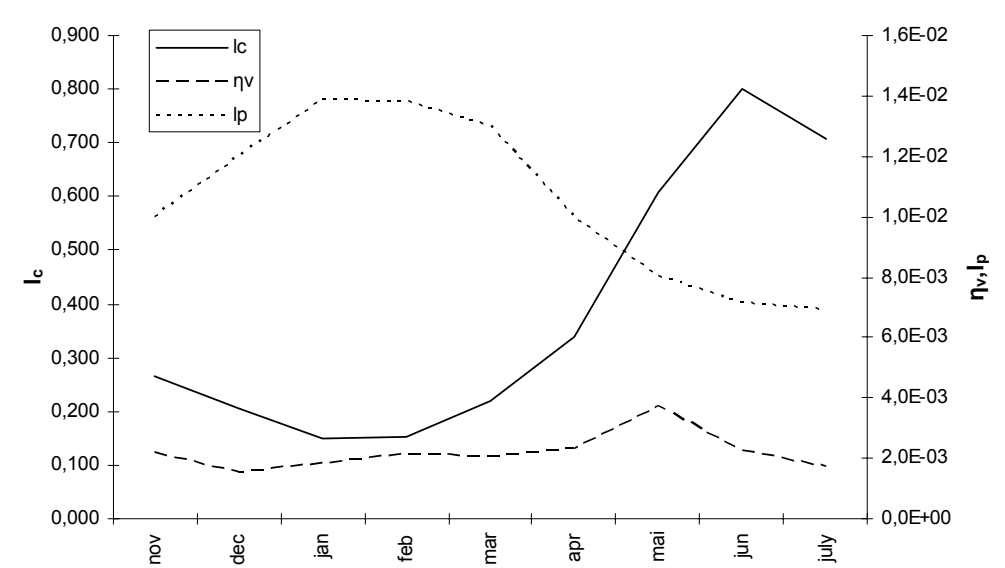

Figure 4c. Monthly variation of length scales $I_{C}, \eta_{V}, I_{p}$ in lake Vegoritis, during 1999- 2000 


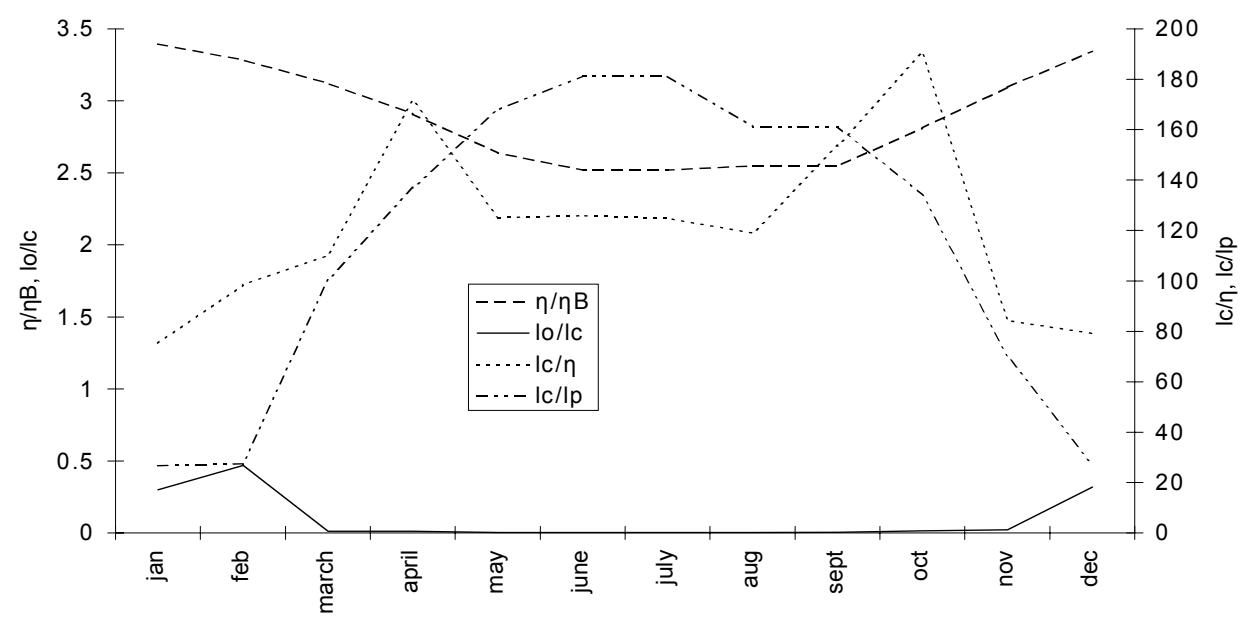

Figure 5a. Monthly variation of length scale ratios $\eta_{v} / \eta_{B}, I_{O} / I_{C}, I_{C} / \eta_{v}, I_{C} I_{p}$ in lake Pamvotis, during 1984

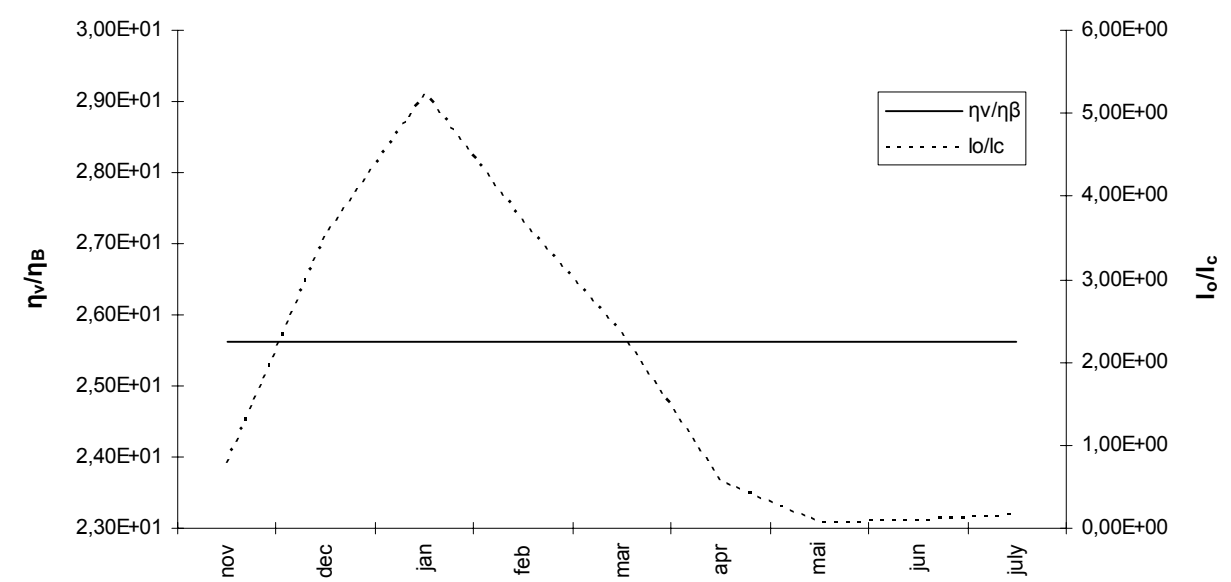

Figure $5 b$. Monthly variation of length scale ratios $\eta_{V} / \eta_{B}, I_{O} \Lambda_{C}$ in lake Vegoritis, during 1999- 2000

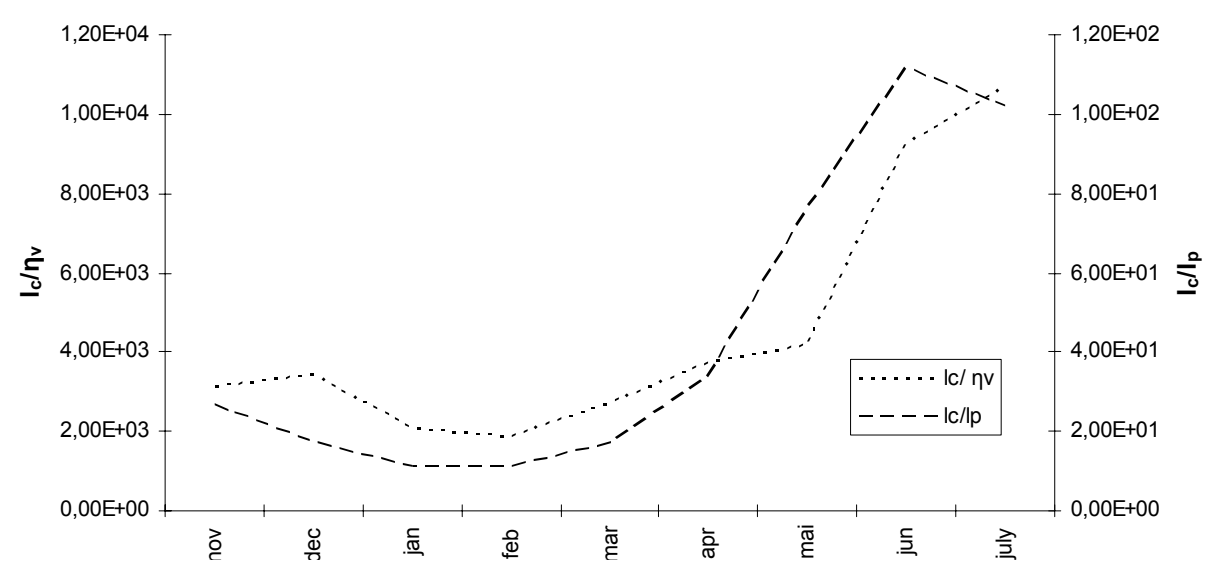

Figure 5c. Monthly variation of length scale ratios $I_{d} I_{p}, I_{C} / \eta_{V}$ in lake Vegoritis, during 1999-2000

For lake Vegoritis, it is seen from Figures $4 c, 5 b$ and $8 b$ that: a) $I_{C}$ remains nearly constant from November of 1999 to March of 2000 and peaks on June - July (of 2000), b) $I_{O}>I_{C}$ from November until the middle of following March - April, whereas for the remaining period of simulation $I_{O}<<I_{C} ; \mathrm{Fr}_{t}$ $>1$ only from the middle of November (of 1999) until the middle of March of the following year. Turbulence remains active during that period, whereas for the remaining simulation period active turbulence occurs at scales smaller than $I_{O}$. It is worth noting that for both lakes the displacement scale, $I_{C}$, remains small, a finding in accord with a similar conclusion of Imberger (1998a) that was 
based on observations from various lakes, indicating that the $I_{C}$ scales are inefficient at transporting mass vertically. For lake Vegoritis, $F r_{Y} \geq 1$-throughout the simulation period- indicating that active turbulence must be present to sustain high rates of strain and cause mixing.

As seen from Figure $6 a$, for lake Pamvotis during 1984 , the ratio $I_{O} / \eta_{V}$ attains maximum values on February and December (of about 45 and 25, respectively) and very low ones from March to November, indicating once more the respective large and small separation between the smallest and largest length scales during the corresponding periods. The ratio $I_{0} / g$ attains maximum values during the stratification period.

For lake Vegoritis, it is seen from Figure $6 \mathrm{~b}$ that the ratio $I_{0} / \eta_{V}$ attains a maximum value on December of 1999, decreases progressively throughout March of 2000 and attains much smaller values during the remaining of 2000 ; the ratio $I_{C} / g$ shows an opposite seasonal variation.

For both lakes, the above picture is consistent with the fact that, in the respective time periods, active turbulence is enhanced (primarily) by convective cooling (and to a lesser extent by wind stirring), but is indeed inhibited by thermal stratification. Figures $1(a, b)$ do confirm the cooling and heating activities during the corresponding periods. Convective mixing activity is certainly more vigorous late in fall and in winter than during spring, summer and early in fall, unless strong wind stirring is occurring during the latter period. Figure $2 a$, confirms that wind stirring is less energetic during the stratification period (May-August). Figure $2 \mathrm{~b}$ shows a somewhat similar behavior, for lake Vegoritis, although during a narrower time span extending from the middle of April to the middle of June of 2000.

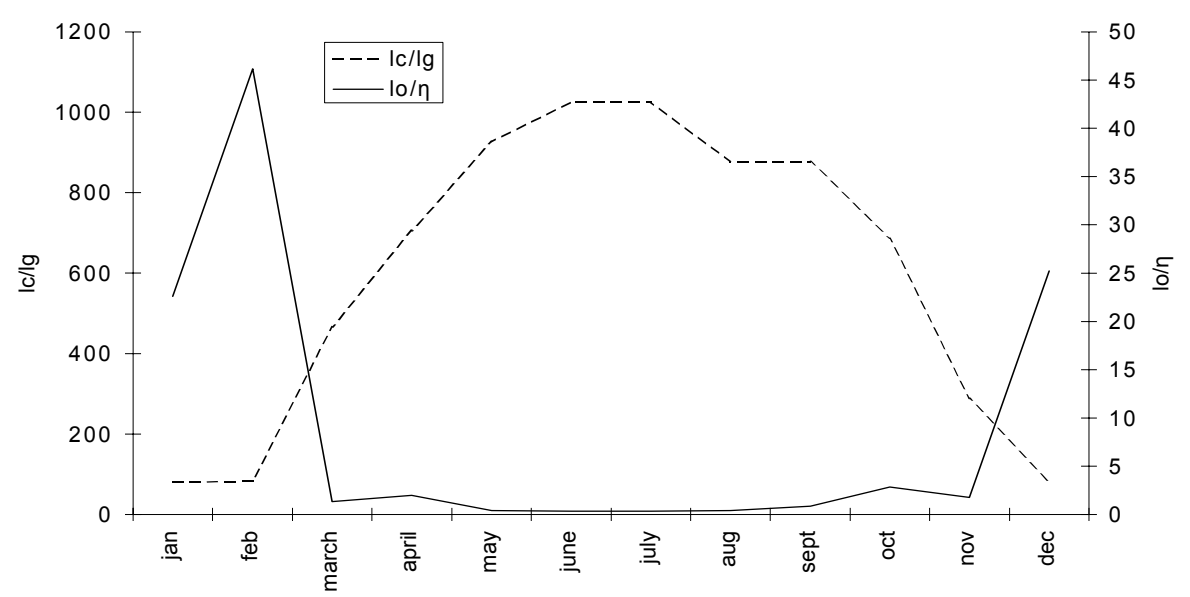

Figure 6a. Monthly variation of length scale ratios $I_{C} l_{g}, I_{O} / \eta_{V}$ in lake Pamvotis, during 1984

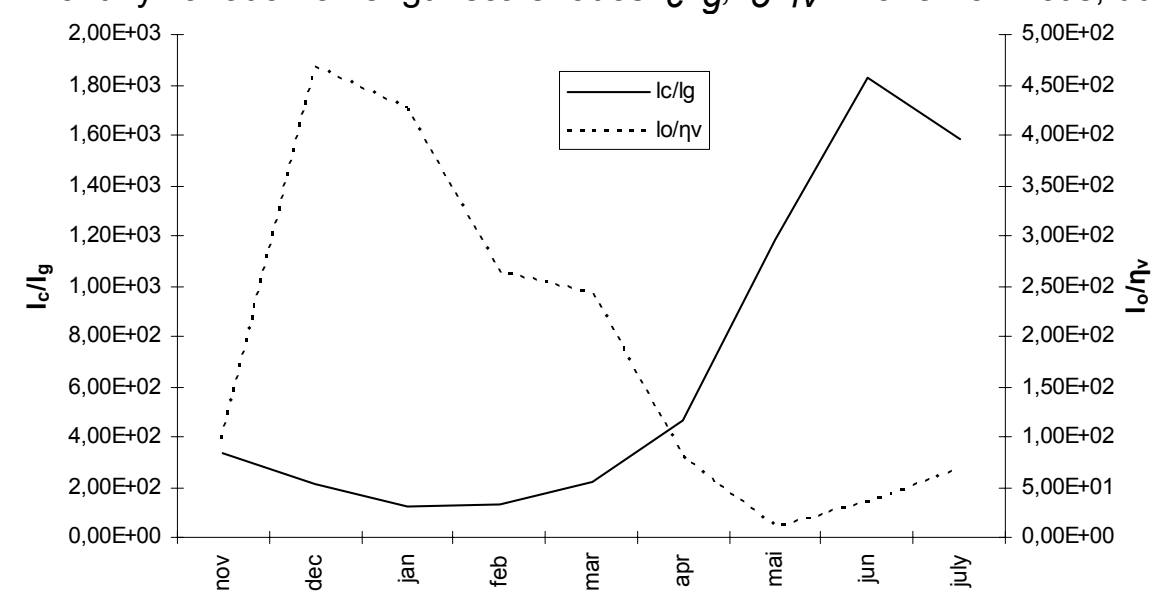

Figure $6 b$. Monthly variation of length scale ratios $I_{C} / l g, I_{0} / \eta_{V}$ in lake Vegoritis, during 1999-2000 


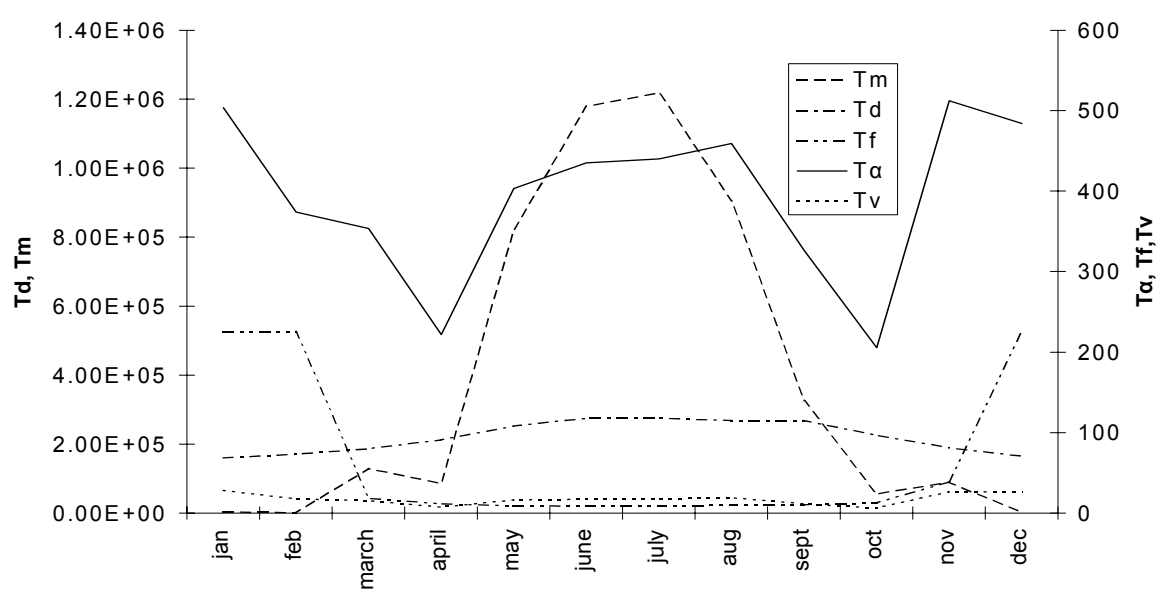

Figure 7a. Monthly variation of time scales $T_{f}, T_{m}, T_{d}, T_{\alpha}, T_{V}$ in lake Pamvotis, during 1984

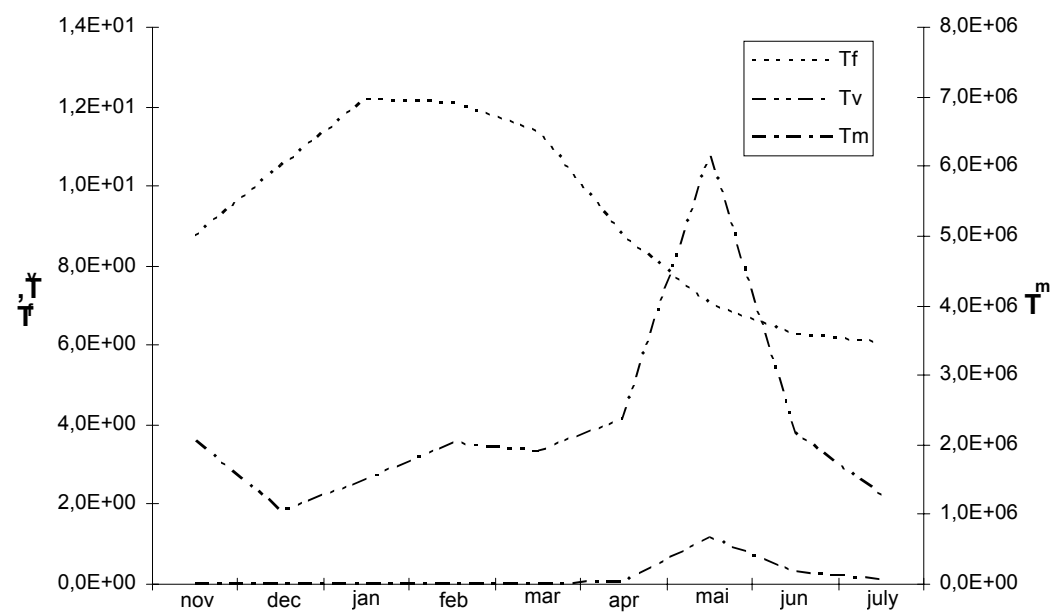

Figure $7 \mathrm{~b}$. Monthly variation of time scales $T_{f}, T_{m}, T_{V}$ in lake Vegoritis, during 1999-2000

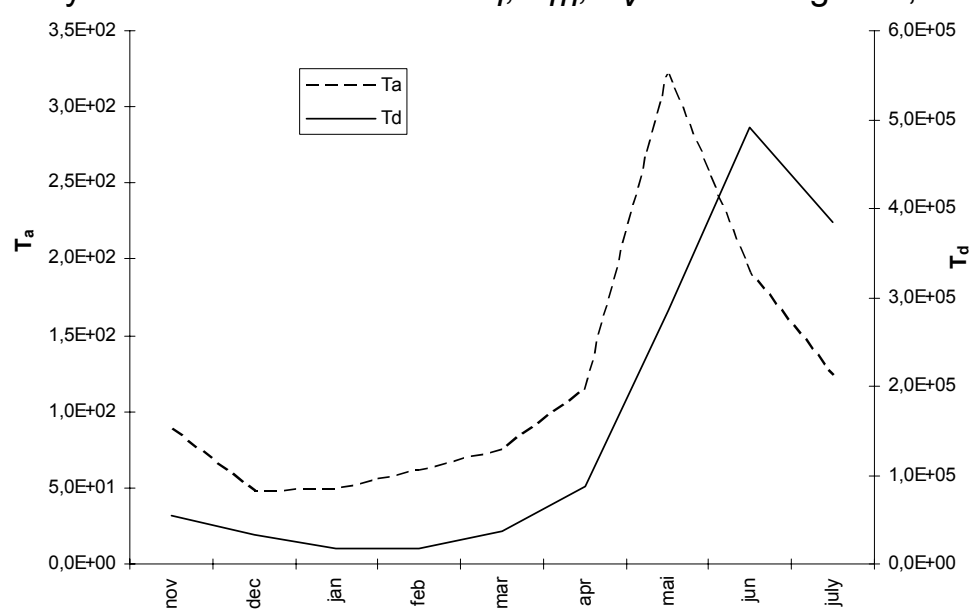

Figure 7c. Monthly variation of time scales $T_{d}, T_{\alpha}$ in lake Vegoritis, during 1999-2000

The (depth-averaged) dissipation rate, $\varepsilon$, for lake Pamvotis is rather low throughout the year (perhaps partly due to its neglect in the billow layer), except around April and October when it becomes an order of magnitude larger. Such a sharp increase in the $\varepsilon$ values, during these periods, may be explained by the fact that, although wind stirring activity is still high, the thermocline forms closer to the surface resulting in smaller values of the mixing layer height, $h$, during the same 
periods. As shown in Figure $9 a, R_{t}$ remains also high, indicating that dissipation rates far exceed viscous dissipation.

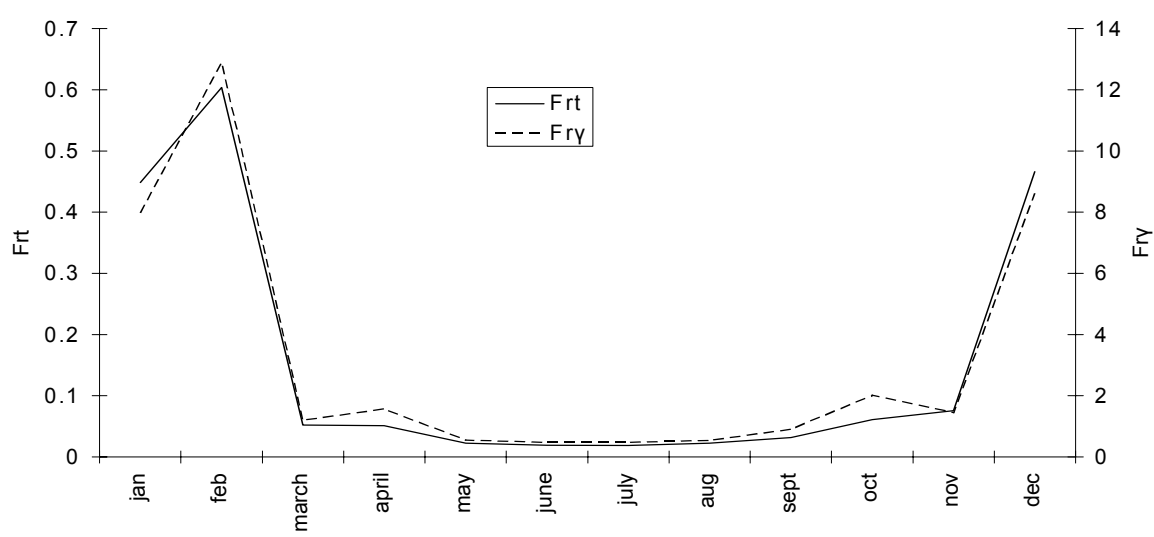

Figure 8a. Monthly variation of $\mathrm{Fr}_{t}$ and $\mathrm{Fr}_{\mathrm{Y}}$ in lake Pamvotis, during 1984

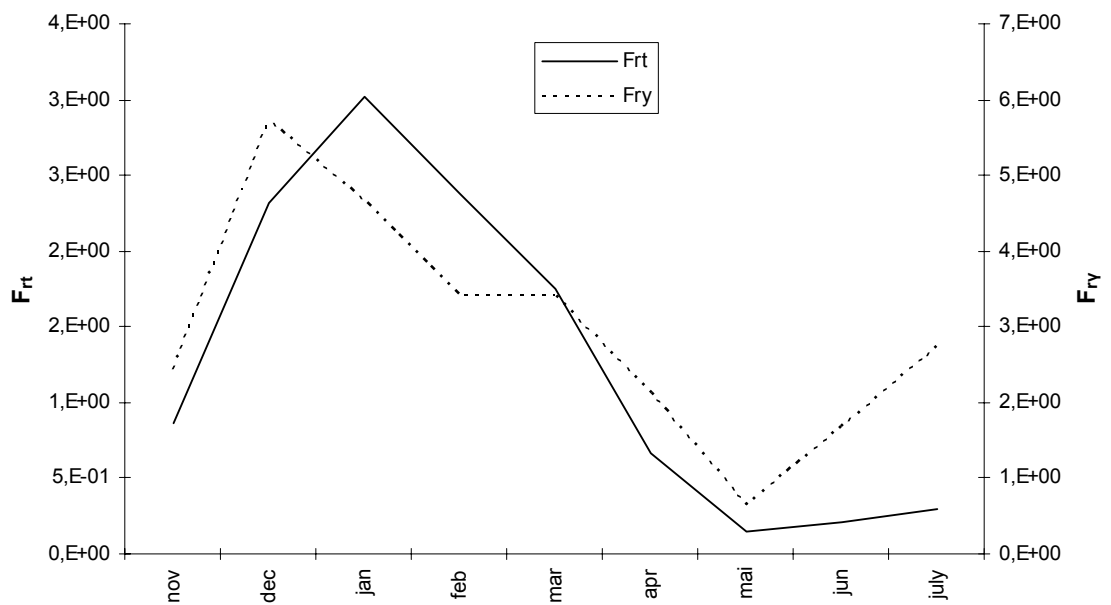

Figure 8b. Monthly variation of $\mathrm{Fr}_{\mathrm{t}}$ and $\mathrm{Fr}_{\mathrm{y}}$ in lake Vegoritis, during 1999-2000

Dissipation, in lake Vegoritis, appears to have a similar behavior with high and low values at rather distinct months, but now these dissipation maxima occur on December of (1999) and on the following July. More precisely, $\varepsilon$ peaks late in fall - early in winter of 1999, remains low from late winter (i.e., middle of February of 2000) to early summer (middle of June of the same year), and shows an increasing tendency as the summer of 2000 progresses. A dissipation minimum appears in May of 2000, in between the low values found from February of 2000 to middle of June. The explanation for the appearance of seasonal $\varepsilon$ maxima is more or less the same as that given for lake Pamvotis. Figure $9 \mathrm{c}$ also shows that always $\operatorname{Re}_{t}>>1$, with exceedingly high values around June and July of 2000, indicating again both the high turbulence activity (and justifying the presence of high $\varepsilon$ values, shown in Figure $3 \mathrm{~b}$ during the corresponding period), and that the turbulence dissipation rates far exceed viscous damping.

It is worth noting that in both lakes, the observed $\mathrm{Fr}_{\mathrm{t}}$ and $\mathrm{Re}_{\mathrm{t}}$ numbers fall within the corresponding range of values found by Lemckert and Imberger (1998), Yamazaki and Ramdsen (1998) and Ivey et al. (1998).

The high values of Lake number $L_{N}$ (for lake Pamvotis), shown in Figure 9a, during late spring, in the summer and early in the fall of 1984 indicate increased turbulence activity in the hypolimnion which perhaps contributes to the thermocline erosion (through entrainment) and deepening.

For lake Vegoritis, it is seen from Figure $9 b$ that the maximum values of Lake number, $L_{N}$, are observed during the summer of 2000, whereas for the remaining period the $L_{N}$ values are close to one. The fact that the Wedderburn numbers, W, remain greater than 10 during the same periods (as also shown in Figures $9 \mathrm{a}$ and $9 \mathrm{~b}$ ) provides additional assurances for the high rate of thermocline deepening resulting in greater mixed-layer depths, $\mathrm{h}$, and, thus, in lower average dissipation rates. 


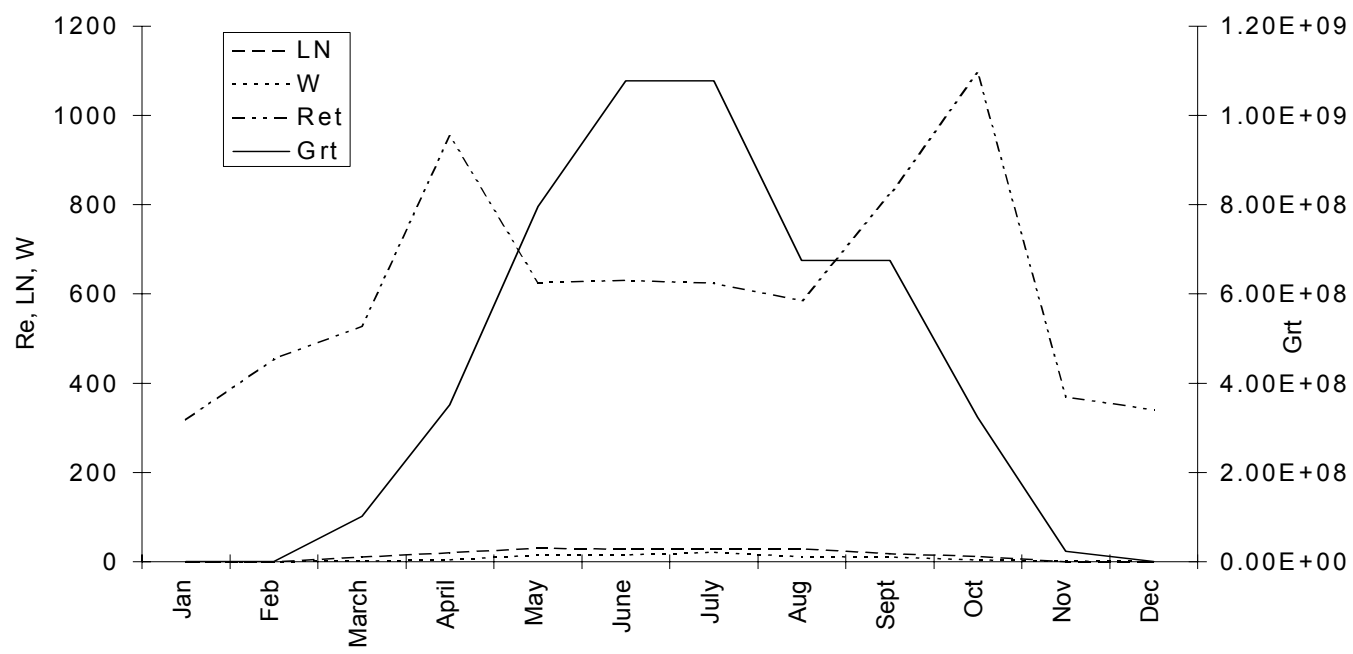

Figure 9a. Monthly variation of $L_{N}, W$, Ret, Grt in lake Pamvotis, during 1984

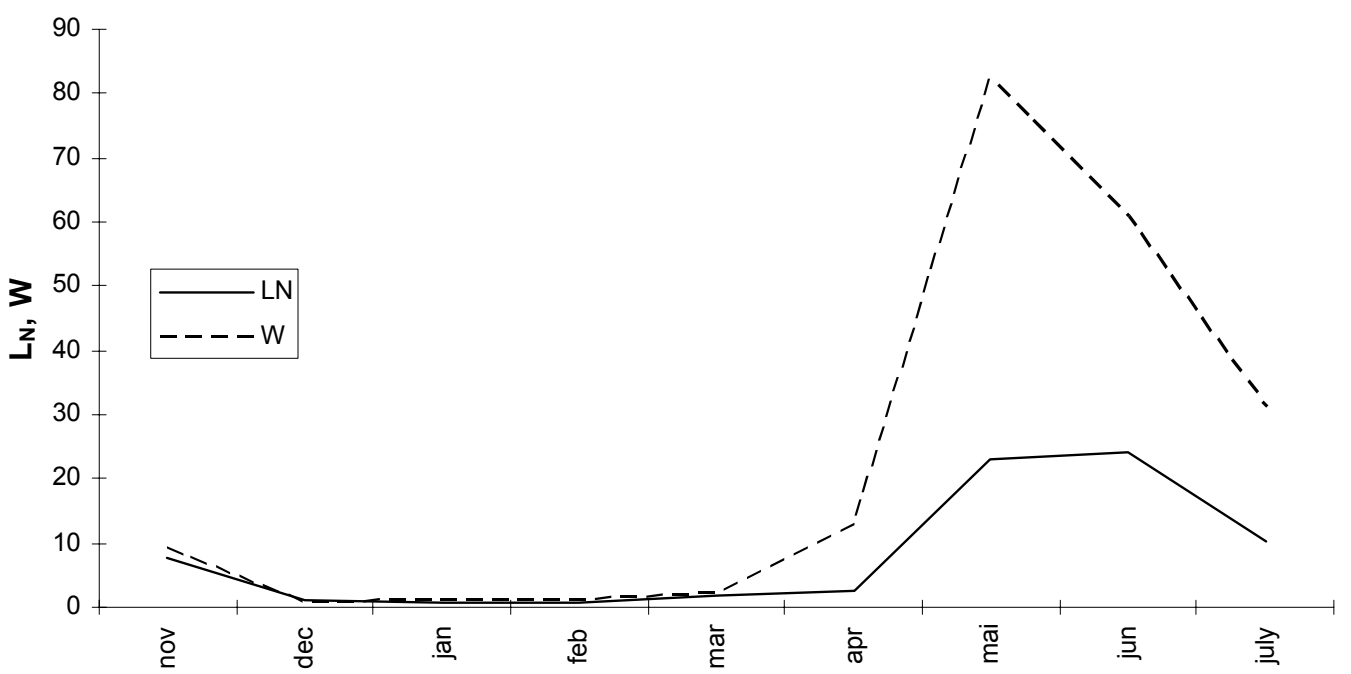

Figure 9b. Monthly variation of $L_{N}, W$ in lake Vegoritis, during 1999-2000

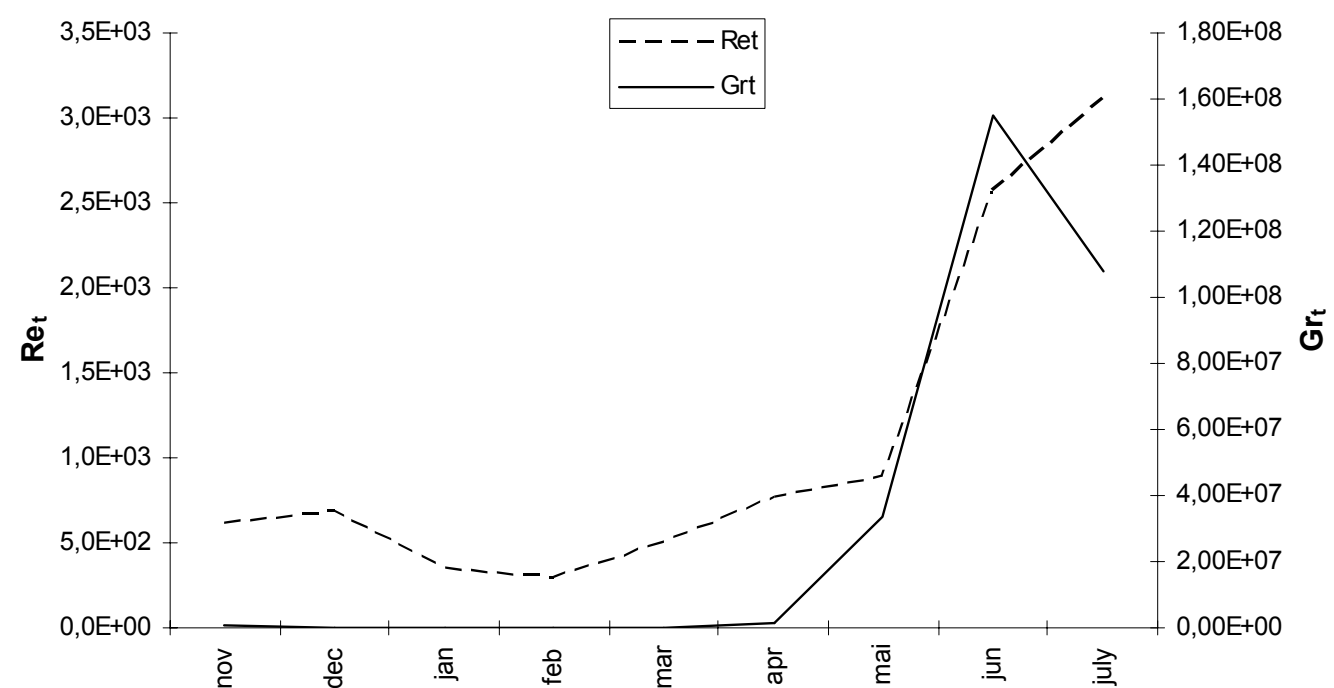

Figure 9c. Monthly variation of $\mathrm{Ret}_{\mathrm{t}}, \mathrm{Gr}$ in lake Vegoritis, during 1999-2000

The high values of Grt, shown in both Figures 9(a, c), from May to July of 1984 and of 2000 (or better from spring of 2000 onwards) indicate that, during the corresponding period, the available potential energy (through stratification) by far exceeds viscous diffusive dissipation, that is the 
turbulent motion outpaces viscous diffusion. It also indicates that the time it takes the turbulent motion to advect lake water one overturn length scale $\left(I_{C}\right)$ is much less than the time it takes for the momentum, associated with the large scale of turbulence, to diffuse by molecular diffusion. The low values of $\mathrm{Gr}_{t}$, found during the remaining periods of simulation in both lakes, indicate that internal wave activity does not persist long as viscous dissipation destroys rapidly internal waves.

From Figure 7a, it may be concluded that, during 1984, the physical processes taking place in lake Pamvotis have periods varying from a few seconds to $10^{6} \mathrm{~s}$; the latter value characterizes $T_{\mathrm{m}}$, the mixing time scale. External forcing (as discussed in Papadimitrakis, 2011) have time scales, associated with diurnal, weekly and seasonal variations of momentum, heat and mass fluxes at the lake surface, ranging from $10^{4}-10^{7} \mathrm{~s}$. Similar conclusions also hold for lake Vegoritis.

In summary, the picture obtained by looking at the evolution of the monthly length and time scales of the various physical processes, for both lakes (Pamvotis and Vegoritis), is consistent with the (evolving) dynamics of these processes throughout the corresponding time period (1984 and 19992000).

Secchi transparency depth (SD) may be used as an indicator of the euphotic zone extent, where significant bio-ecological and other processes take place. From the Secchi transparency data of Theocharis (not shown here; see also Papadimitrakis et al., 1996a) we see that SD in lake Pamvotis varies from 0.5 to $1.5 \mathrm{~m}$, during 1984, depending on the measurement location and the time of the year. These Secchi depths are nearly half the corresponding mixed-layer depths, particularly during late spring, in the summer, and early in the fall. The latter (i.e. mixed-layer) depths are greater than, but consistent with the value of $I_{C} \approx 0.5 \mathrm{~m}$, representing the scale of the largest possible motion. Langmuir cells (if present) are not expected to penetrate deeper than the thermocline mid depth (ranging from about $1.5 \mathrm{~m}$ to $3 \mathrm{~m}$ ) and, thus, they can cycle nutrients into and out the euphotic zone. With transporting velocities of the largest eddies (and possibly of the Langmuir cells, $u_{C}=(\varepsilon / N)^{1 / 2}$, the typical values of $\varepsilon$ and $N$ found in this study and for distances of $\mathrm{O}(1.5) \mathrm{m}$ it may be concluded that plankton circling time in lake Pamvotis will be of order of $10^{3} \mathrm{~s}$, as also commented on, here, before and in Papadimitrakis (2011). A study of the monthly variation of plankton circling time in the epilimnion would require further information on Langmuir circulation velocities, and thus will be avoided.

Secchi disk measurements were not available for lake Vegoritis and thus no pertinent discussion (as for lake Pamvotis) is possible. Yet, since now $I_{C}$ varies between $0.2 \mathrm{~m}$ and $0.8 \mathrm{~m}$ (with an average value of $0.5 \mathrm{~m}$, as in lake Pamvotis) and the mixed-layer depths are always (much) greater than $I_{C}$ (as shown in Figures 8.17-8.31 of Chioni 2005, depicting temperature profiles with depth), it appears that, with the $\varepsilon$ and $N$ values found in Figure $3 \mathrm{~b}$, the plankton circling time in lake Vegoritis will be also of $\mathrm{O}\left(10^{3}\right) \mathrm{s}$. Figure 10 shows the seasonal variation of $u_{c}$ transporting velocities in lake Vegoritis, for the simulation period 1999-2000, confirming that on the average, during that period, $u_{c}=5 \times 10^{-3} \mathrm{~m} \mathrm{~s}^{-1}$.

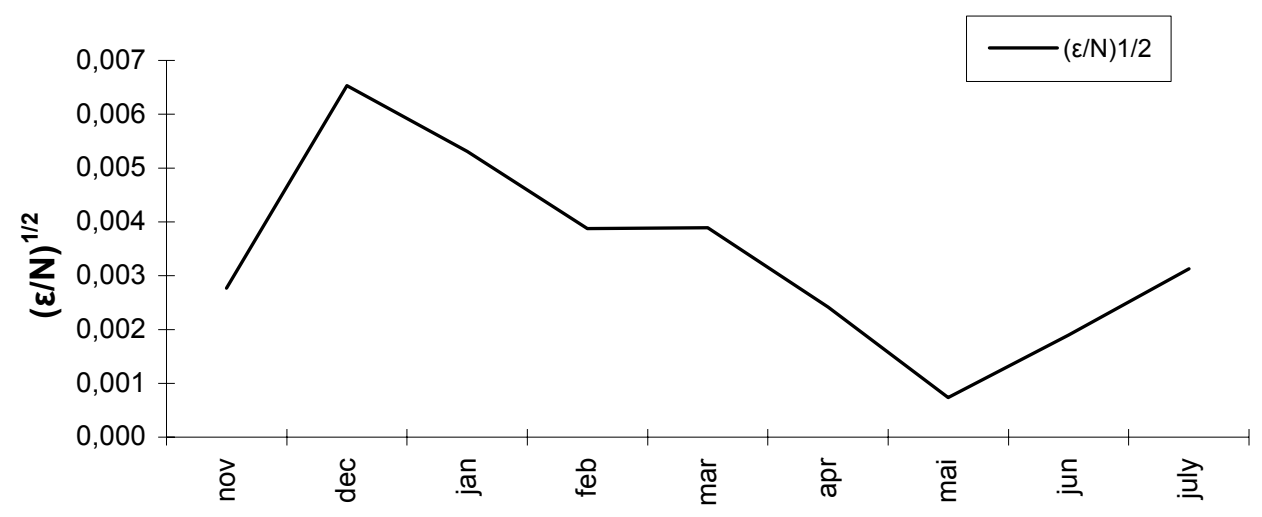

Figure 10. Monthly variation of circling velocities, $u_{c}=(\varepsilon / N)^{1 / 2}$, for lake Vegoritis during 1999-2000 
The above simple analysis provides a first confirmation of the ideas on ecosystem endogenous time scales, window time scales etc. Certainly, there are other ecological processes occurring in both lake Pamvotis and lake Vegoritis with time scales inside the spectral window of the weather of the lake environment or, perhaps, inside the smallscale and mesialscale spectral sub-windows. An investigation of time scales of such processes is beyond the scope of this work and shall become part of future efforts.

\section{CONCLUDING REMARKS}

The basic physical and ecological processes occurring in lakes and the relevant length and time scales, presented in an ecohydrodynamic perspective, were reviewed in Part 1 of our companion paper (Papadimitrakis, 2011). The interaction of physical and ecological processes were reviewed here and their study revealed that the biological activity in lakes occasionally influences the hydrodynamics of these water enclosures. Application of these scaling concepts to lakes Pamvotis and Vegoritis provides a picture of the monthly (and, thus, seasonal) evolution of these scales throughout the year consistent with the dynamics of both the physical processes and other ecological processes in response to the dynamics of external and internal forcing. Simple calculations do confirm the ecohydrodynamic coupling. It appears that the monthly (seasonal) variations of spatial and/or temporal time scales and their ratios in lakes are not greatly affected by the geometry-bathymetry of the lake; they are affected more by external forcing and the generated, in response to the latter, internal forcing which however entails (to some extend) the influence of lake bathymetry and geometry features. Obviously, monthly (and seasonal) smoothing eliminates some other characteristics that the scales examined (and their ratios) could possibly display on a daily basis where the dynamic response of each lake would not only exhibit the detailed influence of external (and internal) forcing but that of the bathymetry as well.

\section{REFERENCES}

1. Chioni A. (2005) Integrated Management of Water Quality in Lakes. Application to Lake Vegoritis. Diploma Thesis, Nat. Techn. Univ. Athens, School of Civil Engrg., Water Res. and Environ. Engrg. Div., Athens, Greece (in Greek).

2. Curry J.A. and Webster P.J. (1999) Thermodynamics of Atmospheres \& Oceans, Intern. Geophys. Series, Vol. 65, AP Publ., Boston.

3. Imberger J. (1998) Physical Processes in Lakes and Oceans. Coastal and Estuarine Studies Series, Vol. 54, Imberger J. (ed.), AGU, Washington D.C.

4. Imberger J. (1998a). Flux Paths in a Stratified Lake: A Review, In: Physical Processes in Lakes and Oceans. Coastal and Estuarine Studies Series, Vol. 54, Imberger J. (ed.), AGU, Washington D.C.

5. Imberger J. and Patterson J.C. (1990) Physical Limnology, In: Advances in Applied Mechanics, Hutchinson J.W. and Wu T. (eds.), AP, Boston.

6. Imboden D.M. (1998) The Influence of Biogeochemical Processes on the Physics of Lakes, In: Physical Processes in Lakes and Oceans. Coastal and Estuarine Studies Series, Vol. 54, Imberger J. (ed.), AGU, Washington D.C.

7. Ivey G.N., Imberger J. and Kossef J.R.(1998) Buoyancy Fluxes in a Stratified Fluid, In: Physical Processes in Lakes and Oceans. Coastal and Estuarine Studies Series, Vol. 54, Imberge, J. (ed.), AGU, Washington D.C.

8. Lemckert C.J. and Imberger J. (1998) Turbulent Benthic Boundary Layer Mixing Events in Fresh Water Lakes, In: Physical Processes in Lakes and Oceans. Coastal and Estuarine Studies Series, Vol. 54, Imberger J. (ed.), AGU, Washington D.C.

9. Lande R. and Wood A.M. (1987) Suspension Times of Particles in the Upper Ocean, Deep Sea Res., 34, 61-72.

10. Maar M., Nielsen T.G., Stips A. and Visser A.W. (2003) Microscale Distribution of Zooplankton in Relation to Turbulence Diffusion, Limnol. Ocean., 48(3), 1312-1325.

11. O'Melia C.R. and Tiller C.L. (1993) Physicochemical Aggregation and Deposition in Aquatic Environments, In: Environmental Particles, Buffle J. and Van Leeuwin H.P. (eds.), Lewis Publ., Boca Raton.

12. Owen R.W. (1989) Microscale and Finescale Variations of Small Plankton in Coastal and Pelagic Environments, J. Mar. Res., 47, 197-240. 
13. Papadimitrakis I. (2011) Temporal and Spatial Scales of Lake Processes. Part 1: Physical and Ecological Scales, Non-Dimensional Parameters and Flow Regimes, Global NEST Journal, 13(4), 339-353.

14. Papadimitrakis I. and Chioni A. (2006) Multilevel Management of Water Quality in Lakes. Application to Lake Vegoritis, In: "Protection and Restoration of the Environment VIII", Gidarakos E., Nikolaidis N., Christodoulatos C., Karatzas E., Diamantopoulos E., Mantzavinos D., Koutsospyros A., Dermatas D., Psillaki E., Paleologos E., Lazaridis M., Koungolos A. and Tsoutsos T. (eds.), Chania, Greece, 4956.

15. Papadimitrakis I., Assimakos G. and Destouni G. (1996a) Dynamic Modelling of Water Quality in Lake Pamvotis. Part I: Physical Processes, Proc. of Intern. Confer. "Protection and Restoration of the Environment III", Diamantopoulos E. and Korfiatis G.P. (eds.), Chania, Greece, 117-124.

16. Papadimitrakis I., Assimakos G. and Destouni G. (1996b) Dynamic Modelling of Water Quality in Lake Pamvotis. Part II: Bio-Geochemical Processes, Proc. of Intern. Confer. "Protection and Restoration of the Environment III", Diamantopoulos, E. and Korfiatis, G.P. (eds.), Chania, Greece, $125-132$.

17. Pedley T.J. and Kessler J.O. (1992) Hydrodynamic Phenomena in Suspension of Swimming MicroOrganisms, Ann. Rev. Fluid Mech., 24, 315-58.

18. Straskraba M. (1998) Coupling of Hydrobiology and Hydrodynamics: Lakes and Reservoirs, In: Physical Processes in Lakes and Oceans. Coastal and Estuarine Studies Series, Vol. 54, Imberger J. (ed.), AGU, Washington D.C.

19. Tiselius P., Nielsen G. and Nielsen T.G. (1994) Microscale Patchiness of Plankton within a Sharp Pycnocline, J. Plankton Res., 16, 543-554.

20. Thomas W.H. and Gibson C.H. (1990) Quantified Small Scale Turbulence Inhibits a Red Tide Dinoflagellate Ganyaulox Polyedra Stein, Deep See Res., 37, 1583-1593.

21. Yamazaki H. and Ramsden D. (1998) Stratified Turbulence: Field, Laboratory and DNS Data. In: Physical Processes in Lakes and Oceans. Coastal and Estuarine Studies Series, Vol. 54, Imberger J. (ed.), AGU, Washington D.C.

22. Weller R.A. and Prize J.F. (1988) Langmuir Circulation Within the Oceanic Mixed-Layer, Deep-Sea Res., 35, 711-747. 